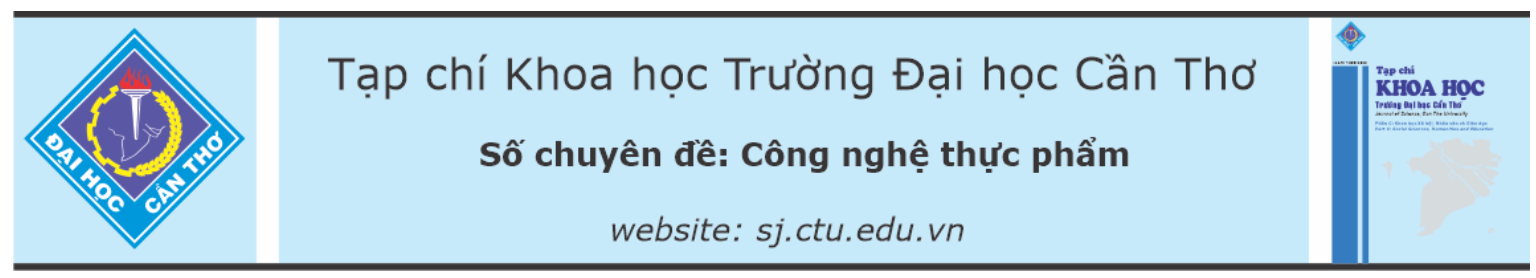

DOI:10.22144/ctu.jsi.2021.016

\title{
KHẢO SÁT MÀNG BAO KHÁNG NÁM BẢO QUẢN QUẢ CAM
}

\author{
Tôn Nữ Liên Hương ${ }^{1 *}$, Nguyễn Thúy $\mathrm{Vi}^{2}$, Lê Thanh Phước ${ }^{1}$ và Nguyễn Minh Hiền ${ }^{3}$ \\ ${ }^{1}$ Khoa Khoa hoc tự nhiên, Truờng Đại học Cần Tho' \\ ${ }^{2}$ Hoc viên cao hoc K26, Khoa Khoa hoc Tư nhiên, Truờng Đại hoc Cần Tho \\ ${ }^{3}$ Khoa Dược, Trường Đại hoc Tôn Đức Thắng \\ *Người chịu trách nhiệm về bài viết: Tôn Nũ Liên Hương (email: tnlhuong @ctu.edu.vn)
}

\section{Thông tin chung:}

Ngày nhận bài: $23 / 02 / 2021$

Ngày nhận bài sủa: 11/03/2021

Ngày duyệt đăng: 28/04/2021

Title:

Investigation on the antifungal coating of oranges

\section{Tù khóa:}

Chitosan, kháng nấm, màng bao bảo quản quả cam, nano $b a c$

\section{Keywords:}

Antimicrobial, chitosan, edible film, preserve orange, nano silver

\begin{abstract}
The aim of study is to produce a safe antifungal polymer membrane surrounding the fruit surface which has the selective gas permeability to minimize biochemical processes and prolong the shelf life of post-harvest oranges. The antimicroorganism envelope was formed from the solution of chitosan, CMC, and silver nitrate mix into ethanol extract of physalis angulata. The fresh oranges were cleaned and dipped in the chitosan emulsion for a certain amount of time. The results showed that most of the processed samples into the preserve are fine for up to 30 days under normal conditions. The weight loss was stable, in addition, the fruit color and hardness did not change significantly, in contrast with the others. With this method, oranges can be better than usual storage, be transported to many places for a long time and are not infected with fungal diseases.
\end{abstract}

\section{TÓM TẮT}

Nghiên cứu nhằm thực hiện màng bao polymer có tính thẩm thấu khí chọn lọc, có chứa chất kháng khuẩn an toàn để tăng thời gian bảo quản quả cam sau thu hoạch. Quả cam tuooi sau khi làm sạch được nhúng vào nhũ tuoong tạo màng gồm dung dịch chitosan kết hợ dung dịch nano bạc ethanol PA trong một thời luợng nhất định. Kết quả cho thấy đối với hầu hết các mẫu được xủ lý qua màng bảo quản thì còn tốt đến 30 ngày ở điều kiện phòng. Độ hao hụt khối luợng quả ổn định, hon nũa cảm quan màu sắc và độ cúng của quả không thay đổi đáng kể; ngược lại các mẫu không xủ lý màng bao mau hu hỏng. Với phuong pháp này, quả cam được bảo quản tốt hơn bình thường, được vận chuyến đi nhiều nơ trong thời gian lâu hơn và không bị nhiểm nấm bệnh.

\section{1. ĐặT VẤN ĐỀ}

Đồng bằng sông Cửu Long có điều kiện thổ nhưỡng và khí hậu phù hợp phát triển cây có múi thuộc chi Citrus, trong đó từ lâu nổi tiếng quả cam sành, sảnh và cam xoàn. Với diện tích trồng trọt và năng suất tiêu thụ rất lớn trong nước, hiện nay loại quả ngon này còn là mặt hàng xuất khẩu đầy triển vọng. Tuy nhiên, do đặc tính sinh học của quả cam mà thường từ 5-7 ngày sau thu hoạch sẽ xuất hiện một số yếu tố ảnh hưởng nghiêm trọng đến chất lượng cũng như giá cả quả cam như: bề mặt quả bị nhăn, màu sắc cảm quan quả từ sắc xanh chuyển vàng, nồng độ vitamin $\mathrm{C}$ giảm, thất thoát khối lượng do mất nước, xuất hiện nẩm nội sinh gây thối quả từ 
cuống,...Việc tạo ra một màng bảo quản giúp kéo dài thời gian lưu giữ, vận chuyển, đồng thời giảm thiểu ảnh hưởng của nấm mốc xanh nội sinh là nhu cầu cấp thiết giữ cho sản lượng quả cam không bị hao hụt trong tình trạng đất ngập mặn xâm chiếm gây ảnh hưởng nghiêm trọng tới năng suất của cây Cam.

Nghiên cứu này đề cập các kết quả bào chế màng bảo quản quả cam bằng cách kết hợp các nguyên liệu có tính kháng vi sinh vật an toàn và có tính hấp phụ khí chọn lọc để bao bọc bề mặt. Với bốn chủng nấm gây thối hư thường gặp trên quả cam nhiễm nấm, việc khảo sát hoạt tính kháng nấm của hệ nhũ tương tạo màng cũng được thực hiện và cho kết quả rất khả quan. sau.

\section{PHƯƠNG TIÊNN VÀ PHƯƠNG PHÁP NGHIÊN CÚ'U}

\subsection{Nguyên vật liệu}

Thí nghiệm được thực hiện từ đầu tháng 9 đến cuối tháng 12 năm 2020.

Cam Xoàn được thu hái ở vườn tại tỉnh Đồng Tháp, vỏ mỏng, có màu xanh, bề ngoài trơn láng, kích thước trung bình 250 đến $300 \mathrm{~g}$, đường kính quả từ 7,5-8,5 $\mathrm{cm}$, và được bảo quản tại phòng thí nghiệm tại khoa Khoa học và Tự nhiên, Trường Đại học Cần Thơ.

Chiết xuất dịch ethanol cây thù lù cạnh, Physalis angulata, để phối hợp cùng các vật liệu khác tạo hệ nhũ tương dịch chiết kháng khuẩn-nano bạcchitosan bao bọc quả cam.

Các hoá chất sử dụng hầu hết xuất xứ Việt Nam, gồm acetic acid (99,5\%), chitosan (>90\%), CMC (carboxymethyl cenllulose), $\mathrm{CaCl}_{2}$, glycerol, PVP (polyvinyl pyrolidone), $\mathrm{AgNO}_{3}$, ethanol (Merck), nước cất.

Máy cô quay Heidolph (Germany), cân phân tích Ohaus, máy khuấy từ gia nhiệt C-MAG HS7 digital.

\subsection{Phương pháp nghiên cứu}

Sơ chế, xử lý nguyên liệu (quả cam) qua clorua vôi và rửa sạch bằng nước. Chiết xuất dịch chiết etanol cây Physalis angulata ( $\mathrm{PA}$, thù lù cạnh) bằng phương pháp ngấm kiệt, sau đó xử lý trong dung dịch bạc nitrat, dung dịch $\mathrm{NaCl}$, PVP tạo thành hệ nano bạc-etanol $\mathrm{PA}$ bằng phương pháp khử hoá học. Phối chế hệ nhũ tương tạo màng bao mau khô từ dung dịch chitosan pha $\mathrm{CMC}$ và hỗn dịch nano bạc trong etanol của $\mathrm{PA}$ theo phương pháp khuấy từ gia nhiệt.
Thử nghiệm trên mẫu giả lập bằng thuỷ tinh để xác định độ dày, trọng lượng màng bao, với cân Ohaus và sử dụng thước kẹp Calipet để xác định độ dày quả cam trước và sau khi tạo màng. Khảo sát kháng nấm đối với dung dịch nhũ bao màng bằng phương pháp xác định đường kính vòng kháng khuẩn và nấm trên đĩa thạch. Đánh giá hoạt tính kháng nấm được dựa vào hiệu suất ức chế theo phương pháp của Adjou et al. (2012) có hiệu chỉnh.

Xử lý, thống kê số liệu bằng One-way ANOVA.

\subsection{Thực nghiệm}

\subsubsection{So chế và xủ lý nguyên liệu}

Cam Xoàn được thu hái vào buổi sáng tại vườn, sau đó xếp vào thùng xốp có đục lỗ (đường kính khoảng $3 \mathrm{~cm}$ ) vận chuyển về phòng thí nghiệm.

Tiến hành làm sạch sơ bộ bề mặt quả băng nước sạch, để ráo. Sau đó, cam được ngâm vào dung dịch có pha sẵn clorua vôi nồng độ $0,0025 \%$ để khử trùng. Sau khoảng 2-3 phút, vớt cam ra ngâm lại với nước cất. Lau khô bề mặt quả nhẹ nhàng.

\subsubsection{Chiết xuất dịch ethanol thù lù}

Bột xay nhuyễn của thù lù được cho vào các túi vải, cột kỹ miệng túi đặt vào bình thủy tinh có nắp, ngâm trong etanol, sau 24 giờ chiết lấy dung dịch, lặp lại nhiều lần và gom dung dịch đem cô quay với áp suất thấp để thu hồi dung môi thu được dịch chiết etanol PA.

\subsection{3. Điều chế hệ nhũ tuoong chitosan kết hơp nano bac PA}

Lần lượt thực hiện các bước: pha $12 \mathrm{~g}$ chitosan với $500 \mathrm{~mL}$ acetic acid $1,5 \%$ và khuấy đều cơ học. Thêm vào hệ $3,0 \mathrm{~g}$ glycerol và $0,5 \mathrm{~g} \mathrm{CMC}$ (đã pha trong $100 \mathrm{~mL}$ nước cất). Tiếp tục khuấy để các thành phần tan đều tạo được dung dịch chitosan.

Điều chếnano bac tù dịch chiết etanol $P A$ và bac nitrat: hoà tan $1,7 \mathrm{~g}$ bạc nitrat vào $100 \mathrm{~mL}$ nước cất, tiến hành định mức nhiều lần để tạo dung dịch bạc nitrat $10^{-3} \mathrm{M}$. Trong cốc chứa $100 \mathrm{~mL}$ dung dịch bạc nitrat thêm vào $50 \mathrm{~mL}$ dịch chiết etanol $\mathrm{PA}$, khuấy từ gia nhiệt ở $50^{\circ} \mathrm{C}$ trong 30 phút, duy trì hệ ở $\mathrm{pH}=5$ với việc thêm acid acetic vào hệ (theo khảo sát riêng trước nhằm xác định điều kiện tối ưu cho phản ứng khử), tạo hệ keo nano bạc-dịch chiết PA.

Pha hệ keo vừa tạo được vào dung dịch chitosan ở trên với tỉ lệ thể tích hệ keo nano bạc-dịch chiết PA:dung dịch chitosan =1:3 thu được hệ nhũ tương tạo màng mau khô. 


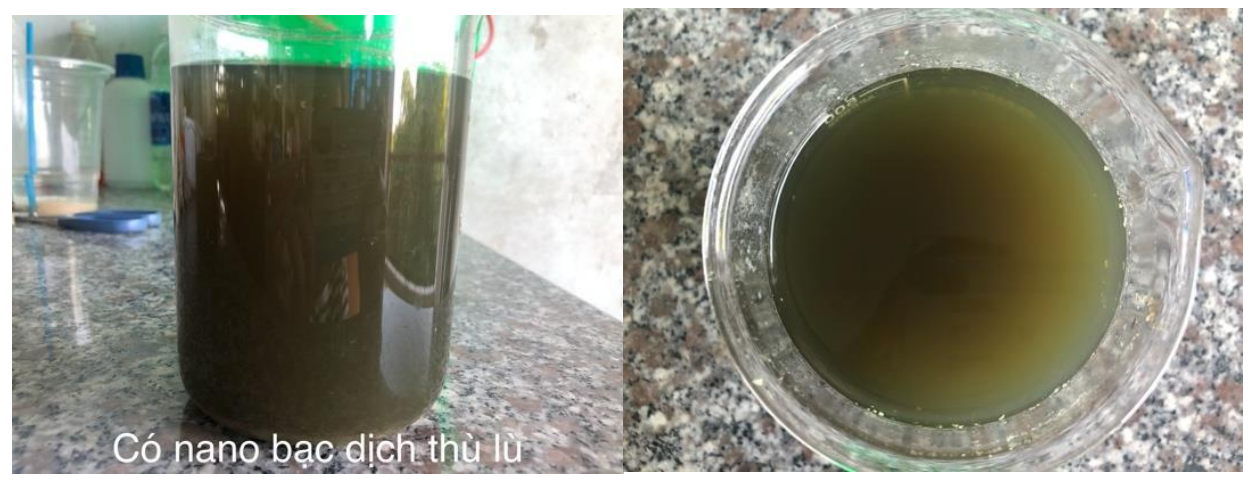

Hình 1. Hệ nhũ tương tạo màng

\subsubsection{Thưc hiện màng bao trên mẫu giả lạp}

Dùng mẫu quả cầu trong suốt có bán kính là 3,3 $\mathrm{cm}$ làm mẫu giả lập, nhúng vào nhũ tương tạo màng. Lần lượt nhúng quả cầu vào nhũ tương tạo màng sau 15 đến 60 giây, để khô tự nhiên, trên bề mặt quả cầu xuất hiện một màng mỏng bao quanh, cần để xác định khối lượng màng. Màng tạo sau ngâm15 giây có khối lượng $0,18 \mathrm{~g}$ và sau 60 giây là $0,24 \mathrm{~g}$.

Khi ngâm quả cam lâu hơn 1 phút, màng tạo dày hơn không đáng kể nhưng quả bị hư sớm hơn trong thời gian quan sát tiếp theo, có thể do bị úng nước.

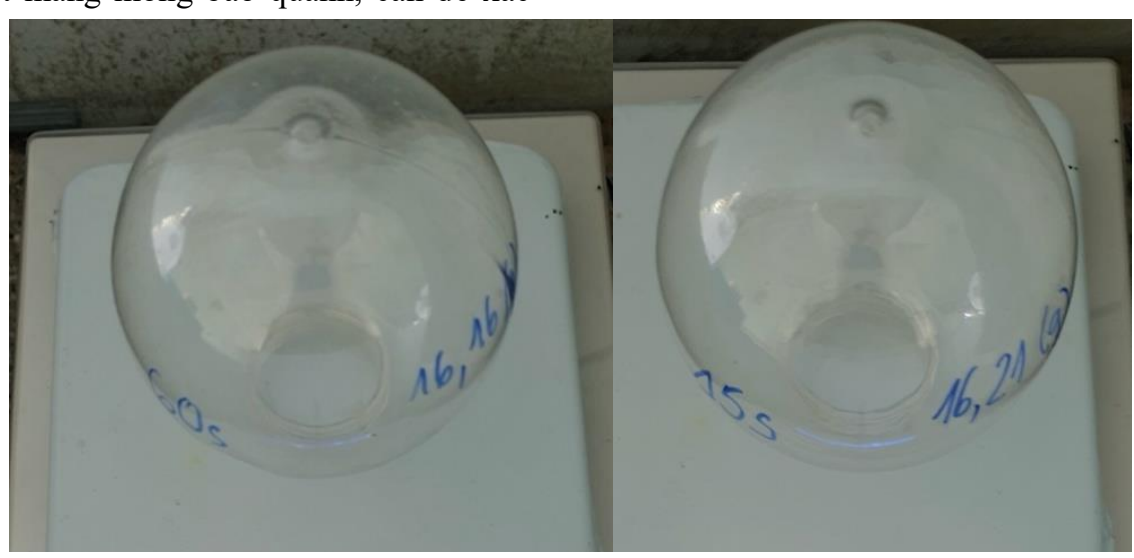

Hình 2. Mẫu giả lập

Nhận xét: Thời gian ngâm quả có thể dao động từ 15 đến 60 giây là hợp lý. Các thí nghiệm với thời gian ngâm lâu hơn quả cam bị ảnh hưởng chất lượng quả.

\subsubsection{Khảo sát hoạt tính kháng nấm của hệ nhũ tuoong tao màng}

\section{* Khảo sát hoạt tính kháng nấm}

Đánh giá hoạt tính kháng nấm được thực hiện theo phương pháp của Adjou et al. (2012) có hiệu chỉnh, ghi nhận hiệu suất ức chế. Môi trường PDA (potato dextrose agar) được chuẩn bị và sau đó lần lượt bổ sung lượng nhũ tương tạo màng (nhũ tương chitosan kết hợp nano bạc-dịch chiết etanol PA gọi là hệ nhũ chibacPA) để đạt được các mẫu thử có nồng độ $(\mu \mathrm{g} / \mathrm{mL}): 0 ; 0,625 ; 1,25 ; 2,5 ; 5 ; 10 ; 20 ; 40$ và 80 . Các chủng nấm hại được đục thành từng mảng nhỏ đường kính $7 \mathrm{~mm}$. Dùng kẹp vô trùng gắp các mảng nấm đặt vào giữa các đĩa petri có chứa hệ nhũ chibacPA. Đường kính vòng nấm được đọc sau 48 và 96 giờ trên đĩa thạch ủ ở $28^{\circ} \mathrm{C}$.

Tỷ lệ ức chế sự phát triển của nấm thí nghiệm bằng màng chibacPA được tính toán bằng công thức của Philippe et al. (2012).

Hiệu suất ức chế sự phát triển của nấm $(\mathrm{H} \%)=$ $\left(\mathrm{R}_{Ð \mathrm{C}}-\mathrm{R}_{\mathrm{T}}\right) / \mathrm{R}_{Ð \mathrm{C}} \times 100$.

Trong đó: $\mathrm{R}_{Ð \mathrm{C}}$ : đường kính nấm phát triển ở mẫu đối chứng âm $(\mathrm{mm}), \mathrm{R}_{\mathrm{T}}$ : đường kính nấm phát triển của nấm trên môi trường PDA bổ sung hệ nhũ tương chibacPA (mm).

* Xác định nồng độ úc chế tối thiểu (minimum inhibitory concentration, $M I C)$ và nồng độ diệt nấm tối thiểu (minimum fungicidal concentration, MFC) 
Nồng độ ức chế tối thiểu (MIC) được định nghĩa là nồng độ nhũ tương tạo màng chibacPA thấp nhất mà tại đó không có sự tăng trưởng nào xảy ra ở nấm sau thời gian thử nghiệm, nghĩa là không có thay đổi về đường kính của nấm, nhưng nấm vẫn còn sống.

Nồng độ diệt nấm tối thiểu (MFC) được định nghĩa là nồng độ nhũ tương tạo màng chibacPA thấp nhất mà tại đó không có sự tăng trưởng nào xảy ra ở nấm do nấm đã chết; nghĩa là không có thay đồi về đường kính của nấm do nấm đã chết. Cách xác định MFC như sau: các đĩa nấm bị ức chế $100 \%$ được cấy lại vào đĩa môi trường PDA bình thường. Sau đó, các đĩa nấm được ủ ở $28^{\circ} \mathrm{C}$ trong 96 giờ và quan sát sự hồi sinh tăng trưởng của các chủng nấm (Adjou et al., 2012).

\subsubsection{Thưc nghiệm nhúng quả tạo màng bao thực tế}

Mỗi lượt chọn 3 quả nhúng vào dung dịch nhũ tương tạo màng trong thời gian lần lượt là 15,30 và 60 giây, sau đó để hong khô tự nhiên trong thùng xốp. Theo dõi ghi nhận hình ảnh cũng như khảo sát về độ khác biệt khối lượng, trạng thái bên ngoài của các mẫu để thống kê.

\section{KẾT QUẢ VÀ THẢO LUẬN}

\subsection{Hình ảnh quả cam thu được sau 24 ngày bảo quản được bao màng}

Thực nghiệm cho kết quả, sau 24 ngày bảo quản và tồn trữ những quả cam được bao màng bằng hệ nhũ tương hầu như không thay đổi về trạng thái bên ngoài, không bị nấm tấn công và gây hư hỏng.
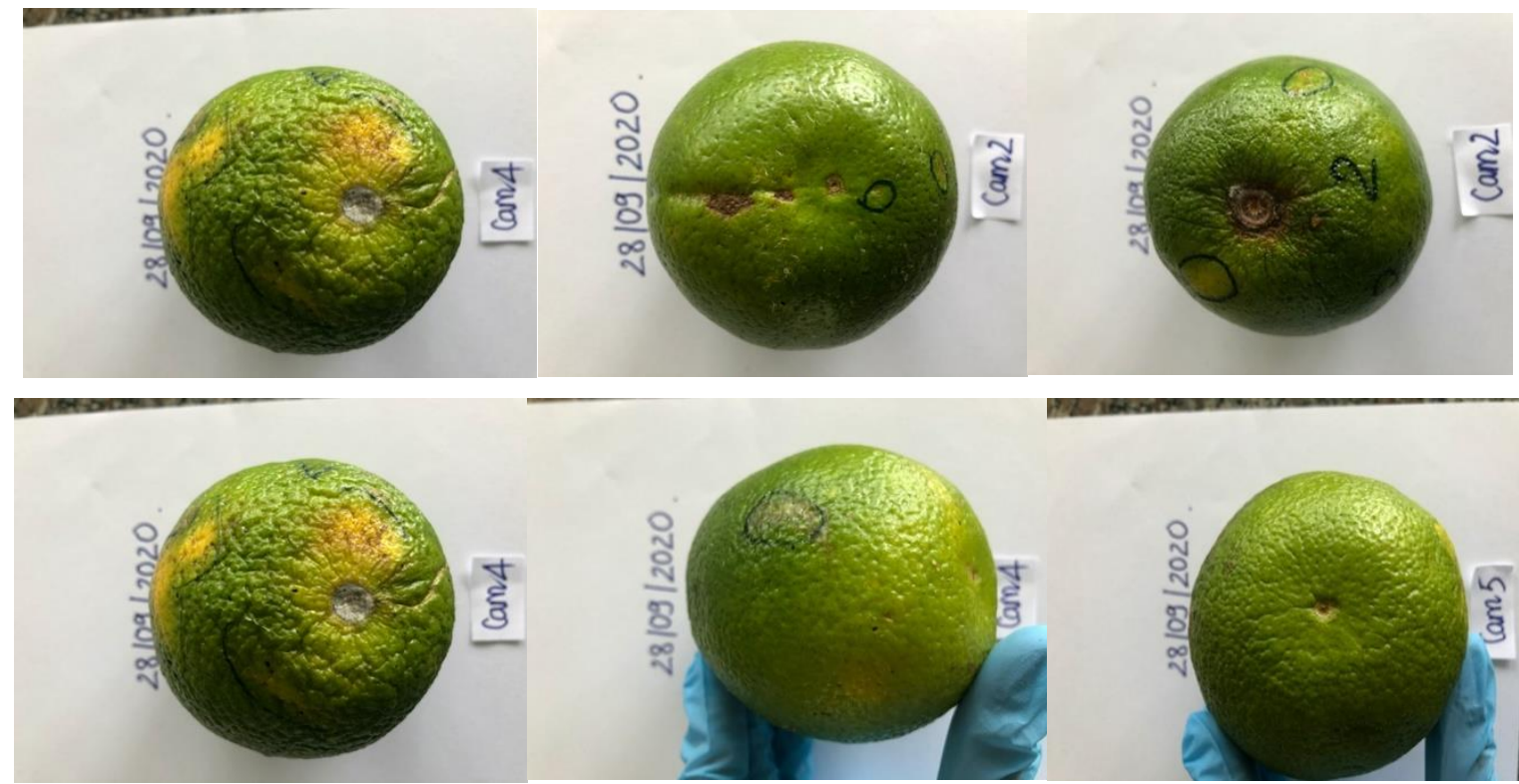

Hình 3. Hình ảnh quả cam Xoàn sau 24 ngày bảo quản

\subsection{Khảo sát hoạt tính kháng nấm của dung dịch nhũ tương tạo màng}

Khảo sát khả năng ức chế của nhũ tương tạo màng chibacPA đối với 4 chủng nấm trên quả cam hư, ký hiệu vNấm-1, Nấm-2, Nấm-3, Nấm-4. Sử dụng các mẫu nhũ tương pha trong môi trường thạch PDA có nồng độ tăng dần tuyến tính từ 0,$625 ; 1,25$; 2,5 cho đến $80(\mu \mathrm{g} / \mathrm{mL})$ để nuôi cấy nấm trên đĩa petri. Các số liệu quan sát đo đạc đường kính vô khuẩn trên đĩa petri được ghi nhận sau 48 và 96 giò̀ và được thống kê ANOVA góp phần xác định hiệu suất kháng nấm, cũng như xác định $\mathrm{MIC}$, ghi trong Bảng 1.
Xác định $M I C, M F C$ : từ hiệu suất kháng nấm được thống kê và thể hiện trong Bảng 1 xác định hệ nhũ tương chibacPA kháng cả 3 chủng nấm gây bệnh quả cam tên Nấm-1, Nấm-2, Nấm-3 đều có MIC là $20,0 \mu \mathrm{g} / \mathrm{mL}$, riêng với chủng Nấm- 4 có MIC là $40 \mu \mathrm{g} / \mathrm{mL}$. Cũng từ Bảng 1 xác định đối với Nấm1, Nấm-2, Nấm-3 đều có MFC là $40,0 \mu \mathrm{g} / \mathrm{mL}$, riêng với chủng Nấm-4 có $\mathrm{MFC}$ là $80 \mu \mathrm{g} / \mathrm{mL}$

Nhận xét kết quả: thực nghiệm đã ghi nhận nhũ tương tạo màng chibacPA có khả năng ức chế rõ rệt đối với 4chủng nấm. Với nồng độ nhũ tương càng cao, hiệu suất kháng nấm càng rõ rệt. Cự thể, ở các nồng độ từ 0,625 đển $10 \mu \mathrm{g} / \mathrm{mL}$ màng vẫn chưa thể ức chế hoàn toàn sự phát triển của nấm gây hại nên 
đường kính khuẩn lạc tăng dần, dẫn đến hiệu suất ức chế có khi giảm. Bắt đầu từ nồng độ trên $10 \mu \mathrm{g} / \mathrm{mL}$ màng bao đã ức chế hoàn toàn sự phát triển của nấm hại. Trong thực tế có thể sử dụng mẫu nhũ tương tạo màng với nồng độ $10 \mu \mathrm{g} / \mathrm{mL}$ cho việc bảo quản hiệu quả các quả cam Xoàn tránh nấm bệnh gây hại.

Bảng 1. Thống kê hiệu suất kháng các chủng nấm của mẫu thử trên đĩa thạch có pha hệ nhũ tương tạo màng chibacPA với nồng độ tăng dần

\begin{tabular}{|c|c|c|c|c|c|c|c|c|}
\hline \multirow{2}{*}{$\begin{array}{c}\text { Nồng } \\
\text { độ } \\
\text { nhũ } \\
\text { tương } \\
\mu \mathrm{g} / \mathrm{mL}\end{array}$} & \multicolumn{2}{|c|}{ Chủng Nấm_1 } & \multicolumn{2}{|c|}{ Chủng Nấm_2 } & \multicolumn{2}{|c|}{ Chủng Nấm_3 } & \multicolumn{2}{|c|}{ Chủng Nấm_4 } \\
\hline & Sau 48 giờ & Sau 96 giờ & Sau 48 giờ & Sau 96 giờ & Sau 48 giờ & Sau 96 giờ & Sau 48 giờ & Sau 96 giờ \\
\hline 0 & $0,00^{\mathrm{g}} \pm 0,00$ & 0,00 & $\overline{0,00}$ & $0,00^{\mathrm{g}}$ & $0,00^{\mathrm{g}} \pm 0,00$ & $0,00^{\mathrm{g}}$ & $0,00 \mathrm{~h} \pm 0,00$ & $0,00 \mathrm{~h}$ \\
\hline 0,625 & $11,65^{\mathrm{f}} \pm 0,70$ & $8,29^{f} \pm 0,51$ & $53,59^{f} \pm 1,93$ & $50,00^{f} \pm 0,93$ & $64,87^{f} \pm 1,35$ & $49,05^{\mathrm{f}} \pm 0,55$ & $65,04^{\mathrm{g}} \pm 0,70$ & $49,02 \mathrm{~g} \pm 0,97$ \\
\hline 1,25 & $20,48^{\mathrm{e}} \pm 3,19$ & $11,25^{\mathrm{e}} \pm 0,89$ & $64,56^{\mathrm{e}} \pm 1,27$ & $52,47^{\mathrm{e}} \pm 0,54$ & $68,92^{\mathrm{e}} \pm 1,35$ & $51,59^{\mathrm{e}} \pm 0,55$ & $68,70^{\mathrm{f}} \pm 0,70$ & $55,18^{\mathrm{f}}$ \\
\hline 2,5 & $33,73^{\mathrm{d}} \pm 2,41$ & $14,50^{\mathrm{d}} \pm 1,36$ & $70,46^{\mathrm{d}} \pm 0,73$ & $56,17^{\mathrm{d}} \pm 0,54$ & $75,68^{\mathrm{d}} \pm 1,35$ & $55,10^{\mathrm{d}} \pm 0,96$ & $72,76^{\mathrm{e}} \pm 0,70$ & $80,95^{\mathrm{e}} \pm 0,49$ \\
\hline 5,0 & $82,33^{\mathrm{c}} \pm 1,84$ & $78,70^{c} \pm 1,54$ & $85,65^{\mathrm{c}} \pm 0,73$ & $83,64^{c} \pm 0,54$ & $83,33^{\mathrm{c}} \pm 0,78$ & $78,66^{c} \pm 0,55$ & $85,77^{\mathrm{d}} \pm 0,70$ & $83,47^{\mathrm{d}} \pm 0,49$ \\
\hline 10,0 & $95,98^{\mathrm{b}} \pm 0,70$ & $89,94^{\mathrm{b}} \pm 0,51$ & $97,89^{b} \pm 0,73$ & $93,83^{\mathrm{b}} \pm 0,54$ & $88,74^{\mathrm{b}} \pm 0,78$ & $84,71^{\mathrm{b}} \pm 0,96$ & $90,24^{\mathrm{c}} \pm 1,22$ & $89,36^{c} \pm 0,49$ \\
\hline 20,0 & $100,00^{\mathrm{a}} \pm 0,00^{\circ}$ & $100,00^{\mathrm{a}} \pm 0,00^{\circ}$ & $100,00^{\mathrm{a}} \pm 0,00^{\circ}$ & $100,00^{\mathrm{a}} \pm 0,00^{\circ}$ & $100,00^{\mathrm{a}} \pm 0,00^{\mathrm{o}}$ & $100,00^{\mathrm{a}} \pm 0,00^{\circ}$ & $93,50^{\mathrm{b}} \pm 0,70$ & $91,86^{\mathrm{b}} \pm 0,48$ \\
\hline 40,0 & $100,00^{\mathrm{a}} \pm 0,00^{*}$ & $100,00^{\mathrm{a}} \pm 0,00^{*}$ & $100,00^{\mathrm{a}} \pm 0,00^{*}$ & $100,00^{\mathrm{a}} \pm 0,00^{*}$ & $100,00^{\mathrm{a}} \pm 0,00^{*}$ & $100,00^{\mathrm{a}} \pm 0,00^{*}$ & $100,00^{\mathrm{a}} \pm 0,00 \mathrm{o}$ & $00,00^{\mathrm{a}} \pm 0,00 \mathrm{o}$ \\
\hline 80,0 & $100,00^{\mathrm{a}} \pm 0,00$ & $100,00^{\mathrm{a}} \pm 0,00$ & $100,00^{\mathrm{a}} \pm 0,00$ & $100,00^{\mathrm{a}} \pm 0,00$ & $100,00^{\mathrm{a}} \pm 0,00$ & $100,00^{\mathrm{a}} \pm 0,00$ & $100,00^{\mathrm{a}} \pm 0,00^{*}$ & $00,00^{\mathrm{a}} \pm 0,00^{*}$ \\
\hline
\end{tabular}

Ghi chú: Kết quả được trình bày duoới dạng giá trị trung bình \pm sai số chuẩn của giá trị trung bình. Thử nghiệm hoạt tính kháng nấm được thực hiện lặp lại 3 lần. Các chũ cái theo sau trong cùng một cột giống nhau thể hiện sụ khác biệt

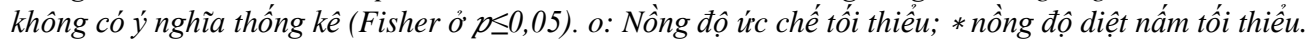

\subsection{Khảo sát sự thay đổi màu sắc vỏ quả sau thời gian bảo quản}

Màu sắc của quả cam trong quá trình lưu trữ, bảo quản, khảo sát trong một tháng được thể hiện và đánh giá theo đồ thị Hình 4 và 5 . Đối với quả cam không bao màng chỉ hơn 10 ngày lưu trữ quả đã hư hỏng. Có nhúng vào nhũ tương tạo màng bao chibacPA để bảo quản quả được giữ nguyên đến 32 ngày.

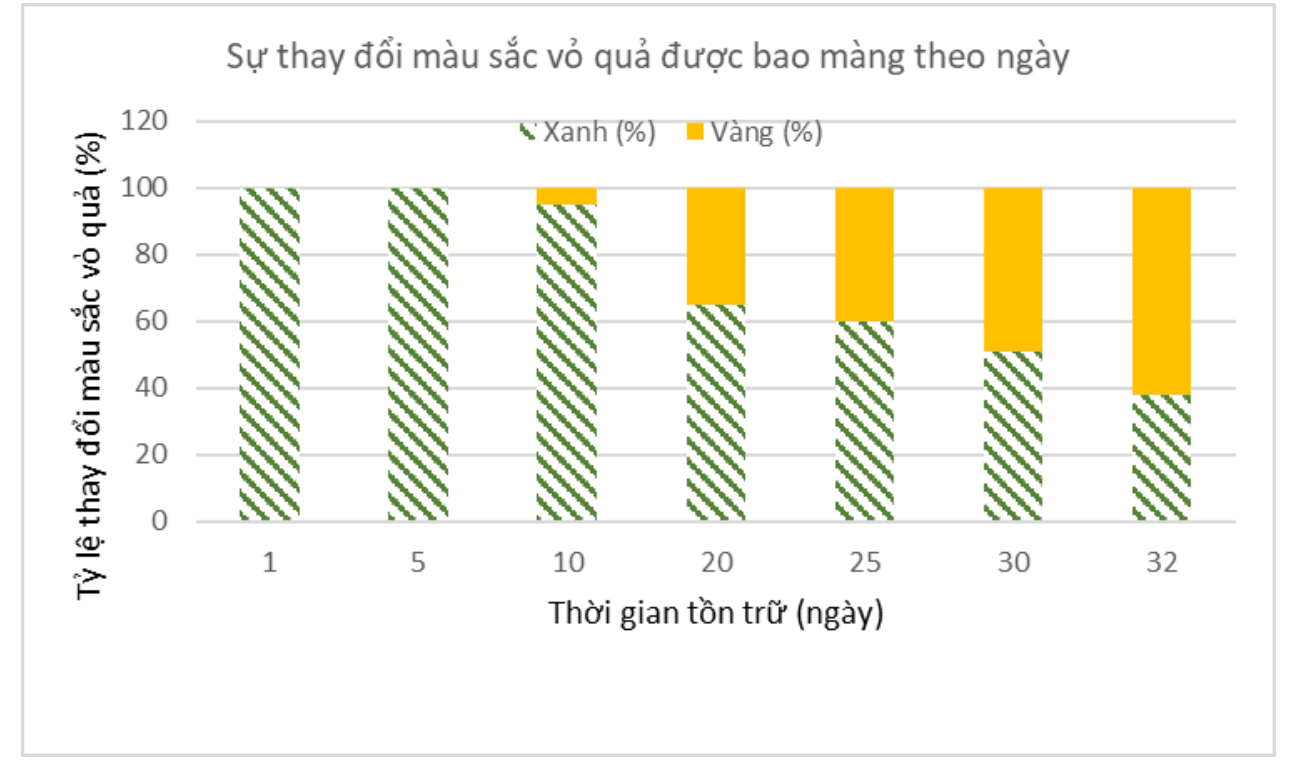

Hình 4. Biểu đồ cột biểu diễn sự thay đổi màu sắc vỏ quả bao màng theo ngày 


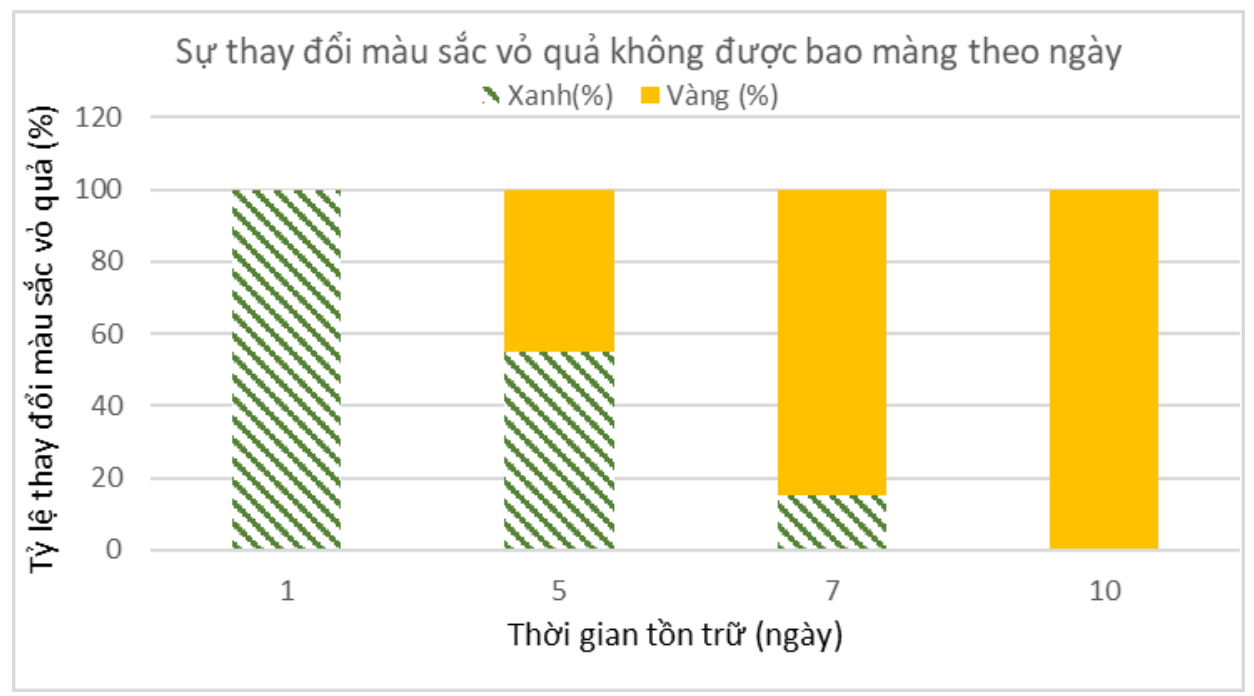

Hình 5. Biểu đồ cột biểu diễn sự thay đổi màu sắc vỏ quả không được bao màng theo ngày

Qua kết quả, có thể thấy ở những quả cam không được bao màng từ ngày thứ 5 sau thu hoạch vỏ quả có sự chuyển màu từ xanh sang vàng cam và đến ngày thứ 7 gần như màu vàng chiếm toàn bộ quả. Ngược lại, ở những quả được bao màng bảo quản thì kéo dài thời gian giữ màu hơn, cảm quan màu xanh của quả hầu như không thay đồi.

Có sự chuyển màu vỏ cam từ xanh sang vàng nhất là ở các quả không được xử lý bao màng, là do ethylen sinh ra từ quá trình hô hấp của quả đã thúc đẩy việc phân huỷ chlorophyll làm mất màu xanh của vỏ quả (Jobling et al., 2002). Còn đối với các quả được bao màng, màng bao bọc ngăn cản lượng
$\mathrm{O}_{2}$ xâm nhập đồng thời cản trở khí $\mathrm{CO}_{2}$ thoát ra nên nồng độ $\mathrm{CO}_{2}$ cao sẽ ức chế etylen sinh ra, làm chậm quá trình chuyển màu của vỏ quả giữ cho màu sắc quả được như ban đầu lâu hơn.

\subsection{Sự thay đổi $\mathbf{p H}$ của dịch quả sau thời gian bảo quản}

Khảo sát độ thay đổi $\mathrm{pH}$ của dịch quả theo thời gian lưu trữ cũng góp phần đánh giá các thay đổi chất lượng quả trong quá trình bảo quản có màng bao. Độ thay đổi $\mathrm{pH}$ của quả có bao màng và quả đối chứng không nhúng nhũ tương tạo màng được đánh giá trong thời gian lưu 25 ngày được thể hiện trong Hình 6.

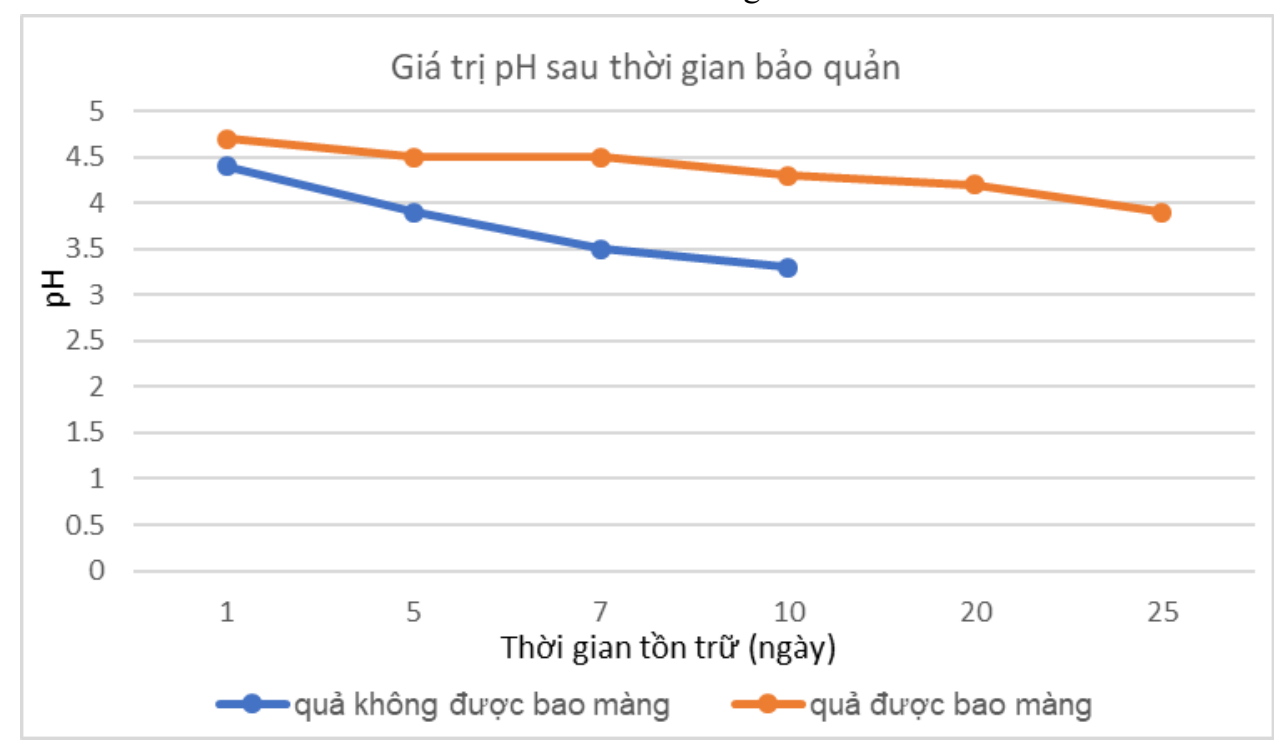

Hình 6. Đồ thị thay đổi giá trị pH sau thời gian bảo quản 
Nhìn chung, giá trị pH của quả cam không được bao màng giảm nhanh chóng sau 5 ngày đầu sau thu hoạch, còn đối với các quả được bao màng bảo quản, quá trình giảm $\mathrm{pH}$ diễn ra chậm hơn. Nguyên nhân của sự giảm $\mathrm{pH}$ là do trong quá trình chín, acid tăng lên và $\mathrm{pH}$ giảm xuống co thể là do sự tạo ra acetic acid và lactic acid trong quá trình bảo quản. Sự phân huỷ các carbohydrate có trong dịch quả do tác động vi sinh vật. Các vi sinh vật xuất hiện gây hư hỏng, tác động đến màu sắc, trạng thái mùi vị của quả (Vũ Kim Dung, 2020).

\subsection{Khảo sát ảnh hưởng của màng bao bảo quản đến tổn thất khối lượng quả cam}

Nhằm đánh giá về độ thất thoát khối lượng quả cam sau thời gian lưu trữ có và không có màng bao bảo quản, các quả cam được nhúng vào nhũ tương tạo màng và không nhúng.

Sau khi cam được ngâm vào dung dịch hệ nhũ tương tạo màng, để ráo trong vòng 24 giờ. Sau đó, cân xác định khối lượng quả. (Thí nghiệm gồm 8 quả, trong đó 2 quả dùng làm đối chứng không ngâm vào hệ nhũ tương). Theo dõi, cân xác định khối lượng quả cam thay đổi hằng ngày. Sau khoảng ngày thứ $5,10,15 \ldots$ thấy khối lượng có sự thay đổi đáng kể nên tính toán xây dựng đồ thị.

Tính tỷ lệ tổn thất khối lượng $(\%)=$ Sự hao hụt khối lượng quả : Khối lượng quả ban đầu (lấy trung bình của các quả cam đem đi làm thí nghiệm)

Sau khi cân, ghi nhận khối lượng các mẫu, kết quả thất thoát khổi lượng thể hiện trong đồ thị

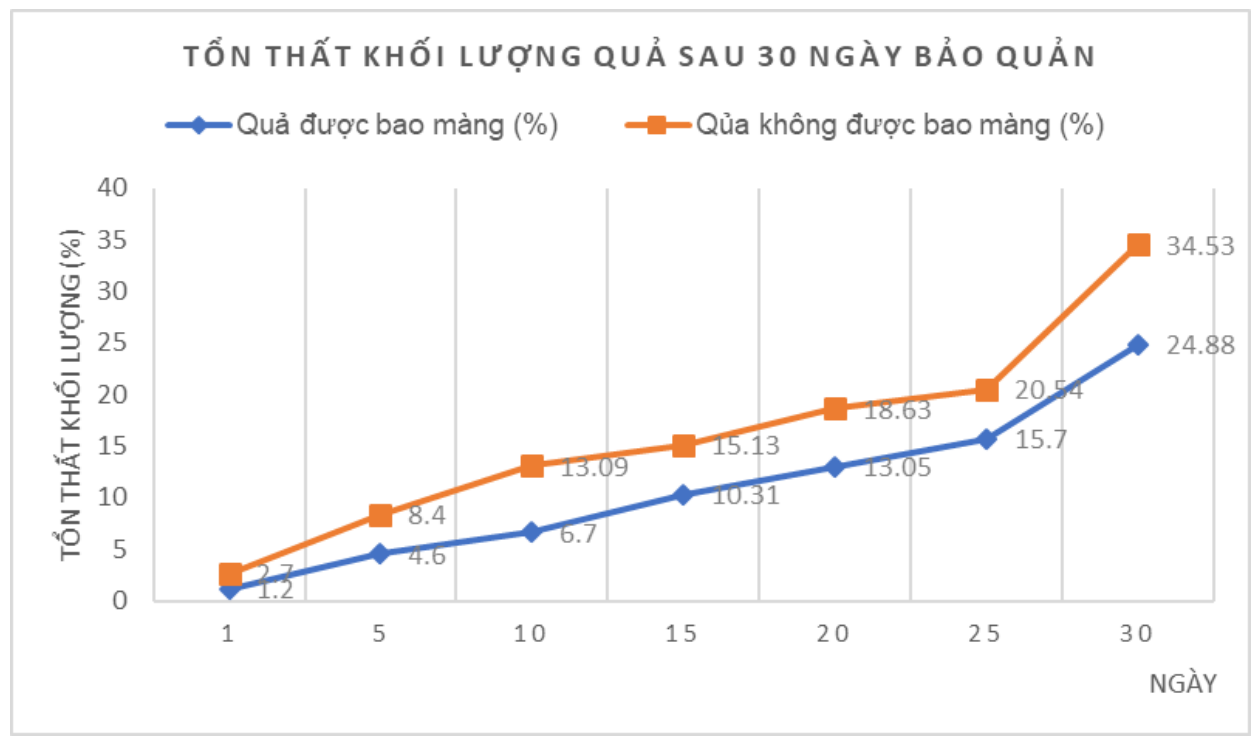

\section{Hình 7. Tổn thất khối lượng quả theo thời gian bảo quản}

Xoá bảng cũ dưới đây vì đã thay bằng bảng số liệu cập nhật

Có thể thấy, sau thời gian bảo quản 1 tháng, ở những quả cam được bao màng nhìn chung mức độ thất thoát khối lượng ít hơn hẳn so với các quả không được bao màng. Sự khác biệt về phần trăm tổn thất khối lượng quả cho thấy hiệu quả của màng bao, giảm sự thoát hơi nước cũng như giảm bớt ảnh hưởng từ các yếu tố môi trường như nhiệt độ, độ ẩm,...làm chậm quá trình thoát hơi nước cũng như quá trình hô hấp của quả nên tỷ lệ thất thoát khối lượng cũng giảm đi.

\section{KẾT LUẬN}

Nhũ tương chitosan kết hợp CMC tạo màng có đặc tính giảm thiểu tính thấm nước và chống ẩm tốt, do đó có khả năng làm chậm quá trình hô hấp. Quả cam tươi sau thu hoạch được bao màng bảo quản này có thời gian lưu trữ lên đến hơn 30 ngày trong khi đối với cam ở điều kiện thường chỉ bảo quản được 5-7 ngày sau khi rời cành.Vậy hệ nhũ tương chibacPA đã bảo quản tốt quả cam nói riêng và các loại quả cùng chi Citrus nói chung, do làm chậm quá trình sinh hoá tiếp diễn của các loại quả có quá trình hô hấp tiếp diễn chậm sau khi thu hoạch.

Bao màng ở thí nghiệm này làm bề mặt quả tươi sáng, giữ được màu sắc vỏ từ lúc thu hái đến bảo quản, tổn thất khối lượng cũng ít hơn so với các phương pháp khác.

Trong thực tế, hoạt tính kháng nấm của dung dịch nhũ tương tạo màng ChibacPA rõ rệt trên 4 dòng nấm đã phân lập từ quả cam bệnh 
Việc bổ sung các hợp chất có tính kháng khuẩn như dịch chiết thảo dược có tính kháng vi sinh vật mạnh như trường hợp ChibacPA làm giảm thiểu sự xâm nhập gây hại của nấm mốc một cách hiệu quả và đặc biệt an toàn với sức khoẻ người tiêu dùng cũng như môi trường sống.

\section{LỜI CẢM ƠN}

Nghiên cứu này được thực hiện với sự tải trợ kinh phí của Chương trình Khoa học và Công nghệ cấp Bộ CT2020-01, TCT05. Nghiền cứu ứng dụng và phát triển công nghệ tiên tiến trong bảo quản, chế biến nông thủy sản vùng Đồng bằng sông Cửu Long, 2020-2021, tại Trường Đại học Cần Thơ.

\section{TÀI LIÊU THAM KHẢO}

Adjou, E.S., Kouton, S., Dahouenon-Ahoussi, E., Sohounhloue, C.K., Soumanou, M.M. (2012). Antifungal activity of Ocimum canum essential oil against toxinogenic fungi isolated from peanut seeds in post-harvest in Benin.
International Research Journal of Biological Sciences, 1(7), 20-26

Philippe, S., Souaïbou, F., Guy, A., Tindo, D.S., Boniface, Y., Azokpota, P., Abdou Karim, Y.I., Sohounloue, K. C. D. (2012). Chemical composition and antifungal activity of essential oil of fresh leaves of Ocimum gratissimum from Benin against six mycotoxigenic fungi isolated from traditional cheese wagashi. Research Journal of Biological Sciences, 1, 22-27.

Jobling, J., McConchie, R., \& Cannon, A. (2002). Practical concepts in Postharvest Biology and Technology. The AusAID CARD project at the University of Sydney and Sydney Postharvest Laboratory, funded by AusAID. University of Sydney and Sydney Postharvest Laboratory. Australia.

Vũ Kim Dung, Phan Thị Hoà \& Nguyễn Thị Hồng Nhung. (2020). Nghiên cứu sản xuất nước ép Dứa (Ananas comosus) - Bí đao (Benincasa hispida) đóng chai. Tạp chí Khoa hoc Công nghẹ Việt Nam, 62(8), 59-64. 